\title{
GHRELIN IN POLYCYSTIC OVARIAN SYNDROME WITH AND WITHOUT DIABETES MELLITUS IN EGYPTIAN POPULATION
}

\author{
Mohamed Elsawy ${ }^{1}$, Mohamed El Abd ${ }^{2}$, Samir Elsheikh ${ }^{3}$, \\ Mohamed Abdelraouf ${ }^{4}$, Ahmed Basyouny ${ }^{3}$ and Yehia Ghanem ${ }^{3}$ \\ Department of Clinical Pathology. Alexandria University I. \\ Department of Obstetrics and Gynecology, Alexandria University 2. \\ Department of Internal Medicine, Alexandria University ${ }^{3}$. \\ Department of Internal Medicine, Menoufeya University 4
}

\section{ABSTRACT}

Background and aim: Ghrelin is a 28 amino acid peptide, which is primarily produced by the stomach. Ghrelin is it strong secretagogue of growth hormone $(\mathrm{GH})$. The polycystic ovary syndrome (PCOS) is traditionally characterized by chronic anovulation, functional hyperandrogenism. Obesity of the central type and Insulin Resistance (IR) are highly associated with the syndrome, predisposing women with PCOS to the development of glucose intolerance and, ultimately, type 2 diabetes mellitus. In the current study, we investigated fasting plasma ghrelin levels in a group of patients with PCOS, with and without type $2 \mathrm{DM}$, and compared with an age matched control group.

Results: Fasting plasma ghrelin was significantly lower in PCOS paticnts than in control groups.

Conclusion: Fasting plasma ghrelin levels were significantly lower in PCOS groups as compared to the control group. Decreased plasma ghrelin levels correlated significantly with Insulin resistance in the patients groups.

\section{INTRODUCTION}

Ghrelin is a 28 amino acid peptide, which is primarily produced by the stomach (1). Ghrelin is a strong secretagogue of growth hormone (GH), exerting its action on the hypothalamic-pituitary system via the GHSR-1A (growth hormone secretagogue receptor- $1 \mathrm{~A})^{(2)}$. Besides its $\mathrm{GH}$-secretagogue properties, ghrelin has also been found to induce the hypothalamic secretion of prolactin and adrenocorticotrophic hormone ${ }^{(3)}$, exert a negative effect on the hypothalamic-pituitaryovarian axis (4), stimulate food intake and positive energy balance (5) and interact with insulin, most probably in a negative feedback circuit, affecting glucose homeostasis (6). Intriguingly, decreased ghrelin levels have been associated with obesity and states of insulin resistance (IR) (7).

The polycystic ovary syndrome (PCOS), probahly the most common endocrine disorder in women of reproductive age, is traditionally characterized by chronic anovulation, funclional hyperandrogenism with or without elevated total androgen levels and polycystic ovaries on ultrasound examination (8).

Obesity of the central type and IR are highly associated with the syndrome, predisposing women with PCOS to the development of glucose intolerance and, ultimately, type 2 diabetes mellitus ${ }^{(9)}$.

Assuming an involvement of ghrelin in the modulation of steroidogenesis as well as glucose aind energy balance, we investigated fasting plasma ghrelin levels in a group of patients with PCOS, with

Corresponding author: Mohamed Elsawy, Department of Clinical Pathology, Faculty of Medicine, Alexandria University. e-mail: melsawy@msn.com. 
and without type 2 DM, and compared with an age matched control group.

\section{MATERIALS \& METHODS}

The study included sixty females from Elshatby University Hospital distributed as follows: Twenty five with PCOS without DM (Group I), Twenty five with PCOS with type II DM (Group II) and ten healthy controls (Group III).

All females were subjected to complete history taking, thorough clinical examination including anthropometric measurements and radiological investigations including Ultasound to establish the diagnosis of PCOS.

Laboratory investigations performed included blood glucose measurements fasting and post prandial, glycosylated hemoglobin, renal function tests and hormonal profile to measure the FSH/LH ratio at day 3 of the menstrual cycle. Fasting serum Insulin was determined and Homeostasis Model Assesment (HOMA index) was calculated using the following formula

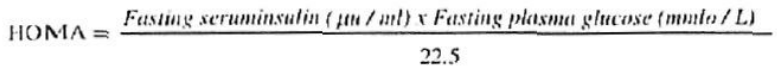

Fasting plasma ghrelin was measured using an ELISA kit (Bioscience Europe SA).Data were processed and analyzed by the software statistical package for social sciences (SPSS). Data were expressed as mean $\pm S D$. Comparison of means between the three groups was done using one way analysis of variance and within groups using paired f-test. Correlation was tested using pearson correlation coefficient. Linear regression analysis was used to compare the different variables. Significance was set at $\mathrm{p}<0.05$.

\section{RESULTS}

\section{Clinical Data}

In group I, the age ranged from 17-32 years with a mean value of $24.8 \pm 3.85$ years. In group II, the age ranged from 26-37 years with a mean value of 31.92 \pm 2.6 years. In group III, the age ranged from 18-29) years with a mean value of $22.7 \pm 3.53$ years.

Four (16\%) subjects in group I had primary amenorrhea, 13 (52\%) subjects had irregular menses and $8(32 \%)$ subjects had regular menses. In group II. $13(52 \%)$ subjects had irregular menses and $12(48 \%)$ subjects had regular menses. In group III all subjects had regular menses.

There was growth of terminal hair in women in the same pattern and sequence as seen in normal men. The hair was present in the hirsute subjects in face. axilla, limbs and trunk. Facial hair was present in moustache and beard with change in quality. size. length and degree of pigmentation. It was present in $15(60 \%)$ subjects in group I and 14 (56\%) subjects in group II. There was a statistical significant difference between the three groups $(p=0.004)$.

Visceral obesity was present in $16(64 \%)$ subjects in group I, 17 (68\%) subjects in group II and none of the subjects in group III. There was a statistical significant difference between the three groups $(p=0.0006)$.

In group I, Waist-hip ratio ranged from 0.72-1.05 with a mcan value of $0.83 \pm 0.08$. In group II. it

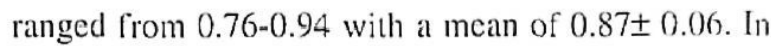
group III, it ranged from $0.72-0.82$ with a mean of $0.78 \pm 0.03$. There was a statistical significant difference between the 3 groups $(f=5.965, p=0.004)$.

\section{Laboratory investigations}

In group 1, FBG ranged from $78-114 \mathrm{mg} / \mathrm{dl}$ with a mean value of $90.68 \pm 9.82$. In group II, it ranged from 168-309 $\mathrm{mg} / \mathrm{dl}$ with a mean value of $210.6+$ 37.7. In group III, it ranged from $74-92 \mathrm{mg} / \mathrm{dl}$ with a mean value of $83.4 \pm 6.28$. There was a statistical significant difference between the 3 groups $([=168.451, p<0.0001)$.

FSH/LH ratio in group I ranged from 0.23-1.33 with a mean value of $0.57 \pm 0.29$. In group II. it 
ranged from 0.26-1.68 with a mean value of $0.69 \pm$ 0.36. In group III. it ranged from 2-2.72 with a mean value of $2.28 \pm 0.27$. There was a statistical significant difference between the 3 groups $(f=114.272, p<0.0001)$ (Table I, Figure 1).

In group I Fasting plasma insulin ranged from $6.8-43 \mathrm{mIu} / \mathrm{mL}$ with a mean value of $21.012 \pm 10.62$ In group II, it ranged from 7.4-56 with a mean of $28.32 \pm 13.35$. In group III, it ranged from $6-11 \mathrm{mLu} / \mathrm{mL}$ with a mean value of $8.35 \pm 1.51$. There was a statistical significant difference between the 3 groups $(\mathrm{f}=11.743, \mathrm{p}<0.0001)$ (Table II , Figure2).

In group I, HOMA index ranged from 1.44-9.12 with a mean value of $4.6313 \pm 2.29$. In group II, it ranged from 3.06-34.05 with a mean value of $14.82 \pm$ 7.73. In group III, it ranged from 1.13-2.38 with a mean value of $1.703 \pm 0.33$. There was a statistical significant difference between the 3 groups $(f=33.482, \mathrm{p}<0.0001)$ (Table III , Figure 3 ).

In group I. serum fasting ghrelin ranged from $0.3-26.5 \mathrm{~F} . \mathrm{moL} / \mathrm{mL}$ with a mean value of $7.27 \pm 8.5$. In group II. it ranged from 1-31 F.moL/mL with a mean value of $9.28 \pm 9.3$. In group III, it ranged from 16.6-38.2 F.moL/mL with a mean value of $25.03 \pm$ 7.8. There was a statistically significant difference between the 3 groups ( $f=15.587, p<0.0001$ ) (Table IV, Figure 4).

There was a significant increase in level of HOMA index in correlation with a decreased level of FSH/LH ratio i.e. PCOS in all three groups (Figure V).

There was a significant decrease in FSH/LH ratio i.e. PCOS in correlation with decreased level of fasting plasma ghrelin (Figure VI).

\section{DISCUSSION}

The syndrome of polycystic ovaries (PCOS) is associated with adiposity and metabolic changes predisposing to insulin resistance and D.M. Women with (PCOS) are at increased risk of type 2 Diabeles mellitus. The overall increase in the incidence of diabetes in women with PCOS is as much as seven times higher than that in control females subjects $1 / 11$. The recently discovered GH-secretagogue ghrelin is intimately involved in the control of appetite and weight regulation (11). Plasma ghrelin levels have been reported to be lower in PCOS women ats compared to control subjects (12).

The present sudy was designed in order 10 atssess the correlation of plasma ghrelin with difleren parameters of the PCOS including metabolic and homonal features. PCOS patients were divided untu two groups: group I including patients withou DM and group II including PCOS with type 2 DM. A control group without PCOS was included. Patients with PCOS in group I and II had characteristic features of primary amenorrhea, irregular menstrual cycle and also hirsutism.

Insulin resistance was noted among PCOS groups. as was noted by a high HOMA index, especially in patients with type 2 DM. Fisting insulin levels were signilicantly higher in those patients. PCOS is a major risk factor for type 2 diabetes mellitus in women regardless of age. O'Meara. et al 1993113, found that lasting hyperinsulinenia is present in obese women with PCOS. This is in part secondirly (w) increased basal secretion rate. The most compelling evidence suggests that beta-cell dysfunction in addition to insulin resistance are l'eatures of PCOS.

In our study, fasting plasma ghrelin levels were significantly lower in PCOS groups as compared to the control group. Decreased plasma ghrelin levels correlated significantly with Insulin resistance in the patients groups.

Ghrelin has attracted attention for its involvement in the control of lood intake and energy balance. when administrated centrally or peripherally to humans, ghrelin enhances appetite, reduces lat utilization and causes adiposity ${ }^{(14)}$, Plasma ghrelin concentration had been shown to be lower in obese patients when compared with normal subjects. 
Therefore conditions characterized by a positive energy balance are associated with low circulating ghrelin concentration ${ }^{(12)}$. Schofl et al, 2002(15) studied the circulating ghrelin levels in patients with PCOS. They confirmed that in PCOS women serum ghrelin levels were significantly lower than in healthy lcan or obese controls. In insulin resistant PCOS women ghrelin levels were significantly lower. There was close correlation of ghrelin to insulin sensitivity. In summary, ghrelin levels are decreased in PCOS women and are highly correlated to the degree of insulin resistance. It was confirmed also by Schofl et al $2002^{(15)}$ that in PCOS women, serum ghrelin levels were significantly lower than in healthy learn or obese controls. Seppo et al (16), confirmed that low ghrelin was associated with high waist circumference, high Body mass Index (BMI), high systolic and diastolic B.P, high fasting blood glucose and plasma insulin. Low ghrelin level is also associated with prevalence of type 2- diabetes and insulin resistance. Low ghrelin level is, independently associated with type 2 diabetes, insulin concentration - insulin resistance and elevated B.P. Therefore it might have some role in type 2 diabetes and regulation of blood pressure.

In conclusion, fasting Ghrelin level decreases in PCOS patients with insulin resistance, with and without DM. It is likely hat mechanisms that result in different clinical and biochemical manifestations of the syndrome might also affect ghrelin concentrations.

\section{REFERENCES}

1. Kojima M, Hosoda H, Date Y, Nakazato M, Matsuo $\mathrm{H}$ and Kangawa $\mathrm{K}$, Ghrelin is a growthhormone-releasing acylated peptide from stomach. Nature (1999); 402,656-660.

2.Howard AD, Feighner SD, Cully DF, Arena JP, Liberator PA, Rosenblum CI, Hamelin M, Hreniuk DL, Palyha OC, Anderson J et al., A receptor in pituitary and hypothalamus that functions in growth hormone release. Science (1996); 273, 974-977.

3. Arvat E, Di Vito L, Maccagno B, Broglio F, Boghen $M F$, Deghenghi $R$, Camanni $F$ and Ghigo E, Effects of GHRP-2 and hexarclin, two synthetic GH-relcasing peptides, on GH, prolactin, ACTH and cortisol levels in man. Comparison with the effects of GHRH, TRH and hCRH. Peptides (1997); 18. 885-891.

4. Van Der Lely AJ, Tschop M, Heiman M and Ghigo E, Biological, physiological, pathophysiological, and pharmacological aspects of ghrelin. Endocr Res (2004) ; 25,426-457.

5. Horvath TL, Diano S, Sotonyi $P$, Heiman $M$ and Tschop M, Minireview: ghrelin and the regulation of energy balance-a hypothalamic perspecuve. Endocrinology (2001) : 142,416-4169.

6. Wierup N, Svensson H. Mulder $H$ and Sundler F. The ghrelin cell: a novel developmentally regulated islet cell in the human pancreas. Regul Pept (2002): 107. 63-69.

7. Tschop M, Weyer C, Tataranni PA, Devanaryan V. Ravussin E and Heiman ML, Circulating ghrelin levels are decreased in human obesity. Diabeles (2001); 50, 707-709.

8. Zawadski JK and Dunaif A, Diagnostic criteria for polycystic ovary syndrome, Towards a rational approach. In Dunaif A, Givens JR, Haseltine FP, and Merriam GE (eds) Polycystic Ovary Syndrome. Current Issues in Endocrinology and Metabolism. Blackwcll Scientific Publications, Boston, MA. USA. (1992) ; pp. 377-384 .

9. Goodarzi MO and Korenman SG. The impontance of insulin resistance in polycystic ovary syndrome. Fertil Steril (2003): 80, 255-258.

10. Dahlgren E, Johansson S. Lindstedt G, et al: Women with polycystic ovary syndrome wedge resected in 1956 to 1965: A long-term follow-up focusing on natural history and circulating hormones. Fertil Steril (1992); 57: 505.

11. Dunaif A: Insulin resistance and the polycystic ovary syndrome: Mechanisms and implications for pathogenesis. Endocr Rev (1997); 18:774-800.

12. Tschop M. Weyer C. Tataranni AP, Devanarayan V. Ravussin E, Heiman ML. Circulating ghrelin levels are decreased in human obesity. Diabetes (2001); 50:707-9.

13. O'Meara NM, Blackman JD, Ehnnann DA, et al: Defects in beta-cell function in functional ovarian hyperandrogenism. J Clin Endocrinol Metab (1993): $76: 1241-7$

14. Tshop M, Smiley DL, Heiman ML. Ghrelin induces adiposity in rodents. Nature (2000); 407: 908-13.

15. Schofl $\mathrm{C}$, et al. Circulating ghrelin levels in patients with polycystic ovary syndrome. J Clin Endorcrinol Metab (2002); Oct; 87(10): 4607-10.

16. Scppo M., et al Law plasma ghrelin is associated with insulin resistance, hypertension and the prevelemce of type 2 Diabetes. Diabetes (2003): Oct; vol. 52: 2546 
Table I: $\mathrm{FSH} / \mathrm{LH}$ ratio .

\begin{tabular}{|l|c|c|c|}
\hline & Group I & Group II & Group III \\
\hline Range & $0.23-1.33$ & $0.26-1.68$ & $2-2.72$ \\
\hline Mean & 0.57 & 0.69 & 2.28 \\
\hline SD & \pm 0.29 & \pm 0.36 & \pm 0.27 \\
\hline
\end{tabular}

Table II : Fasting insulin levels .

\begin{tabular}{|l|c|c|c|}
\hline & Group I & Group Il & Group III \\
\hline Range & $6.8-43$ & $7.4-56$ & $6-11$ \\
\hline Mean & 21.012 & 28.32 & 8.35 \\
\hline SD & \pm 10.62 & \pm 13.35 & \pm 1.51 \\
\hline
\end{tabular}

Table III : HOMA index.

\begin{tabular}{|l|c|c|c|}
\hline & Group I & Group II & Group III \\
\hline Range & $1.44-9.12$ & $3.06-34.05$ & $1.13-2.38$ \\
\hline Mean & 4.631 & 14.820 & 1.703 \\
\hline SD & \pm 2.29 & \pm 7.73 & \pm 0.33 \\
\hline
\end{tabular}

Table IV : Fasting plasma Ghrelin .

\begin{tabular}{|l|c|c|c|}
\hline & Group I & Group II & Group III \\
\hline Ringe & $0.3-26.5$ & $1-.31$ & $16.6-38.2$ \\
\hline Muin & 7.27 & 9.28 & 25.03 \\
\hline $\mathrm{SD}$ & \pm 8.5 & \pm 9.3 & \pm 7.8 \\
\hline
\end{tabular}




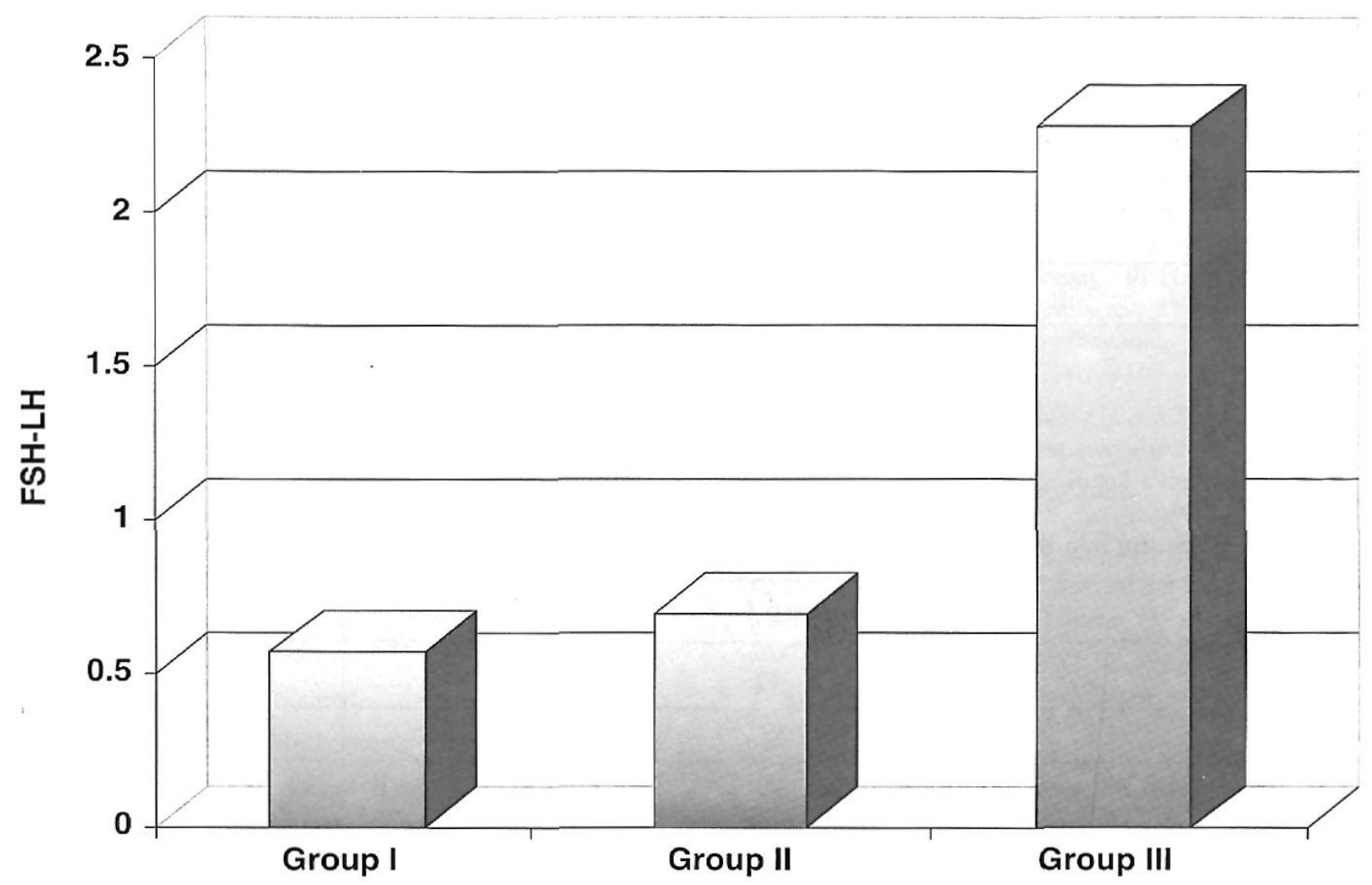

Figure 1: FSH-LH in the 3 studied groups

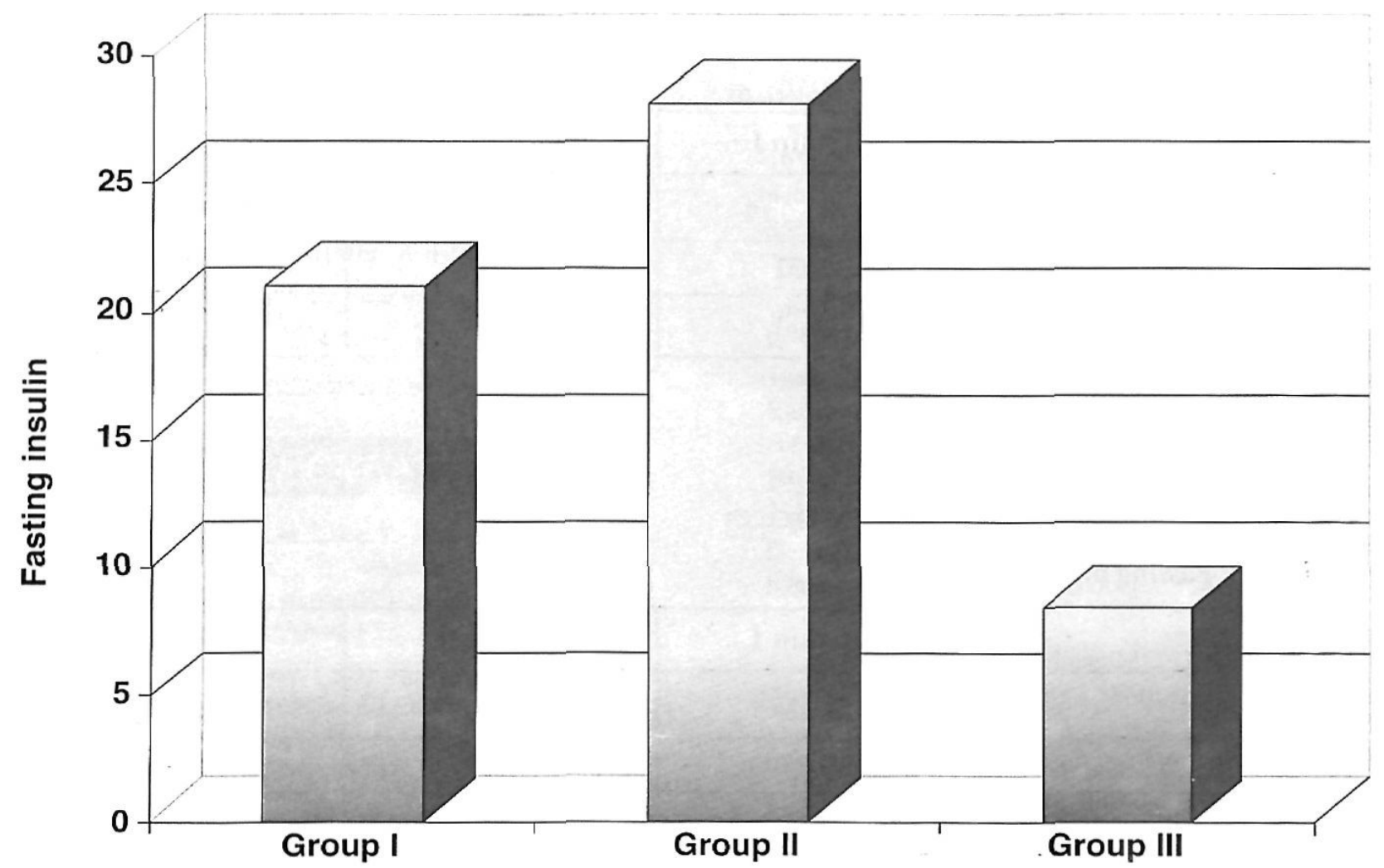

Figure 2 : Fasting plasma insulin in the 3 studied groups 


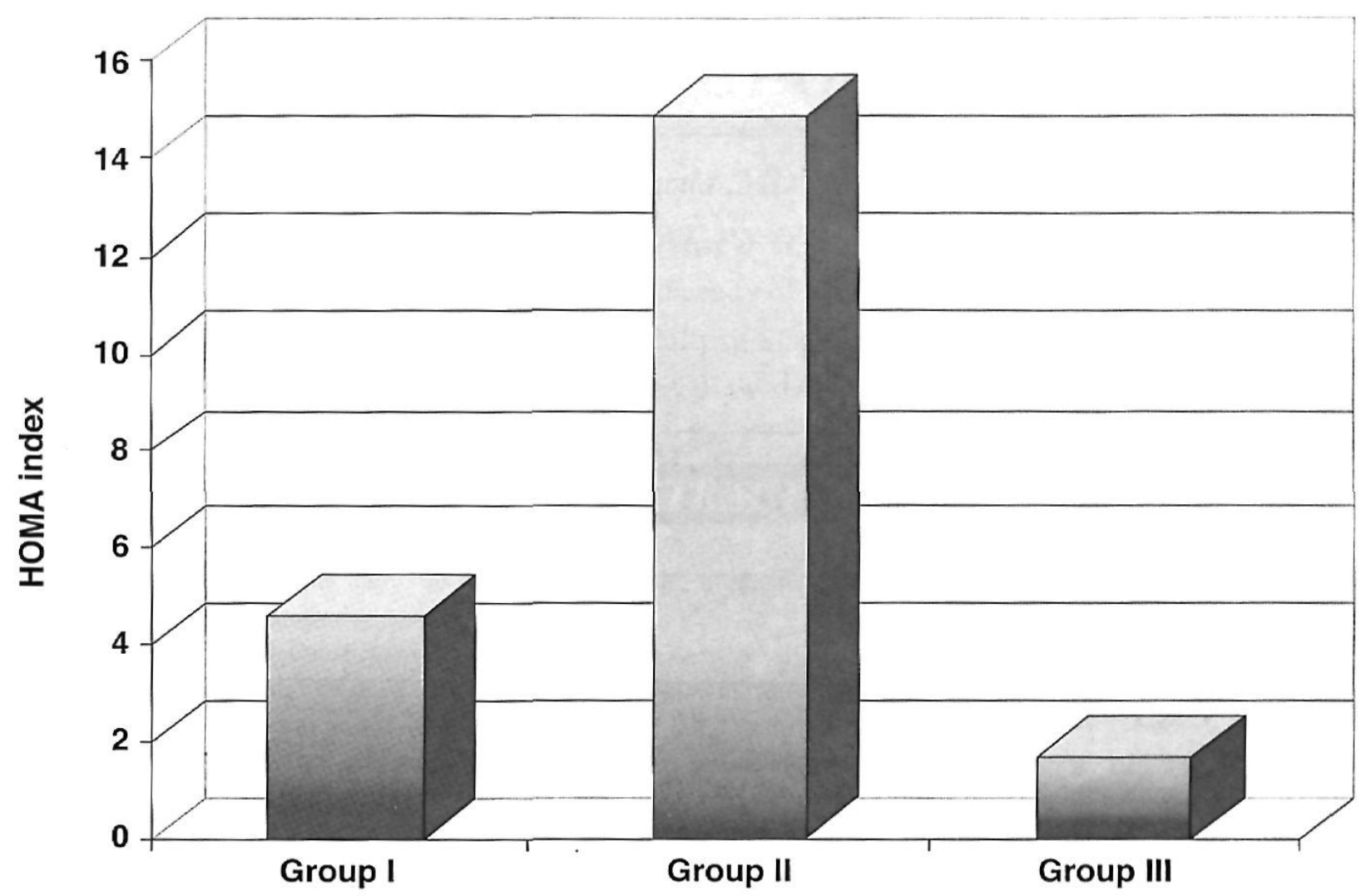

Figure 3: HOMA index in the 3 studied groups

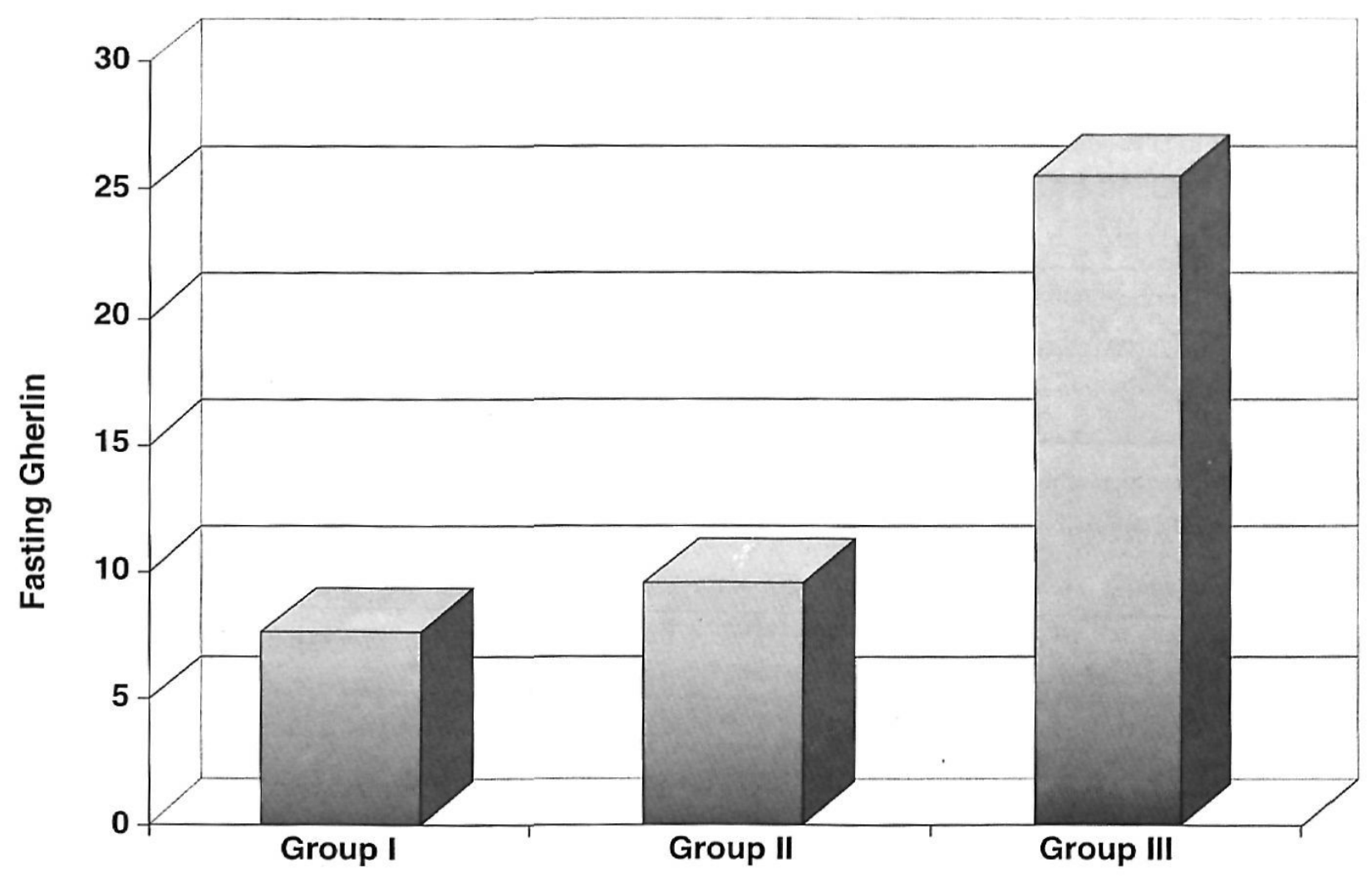

Figure 4: Fasting plasma Ghrelin in the 3 studied groups 


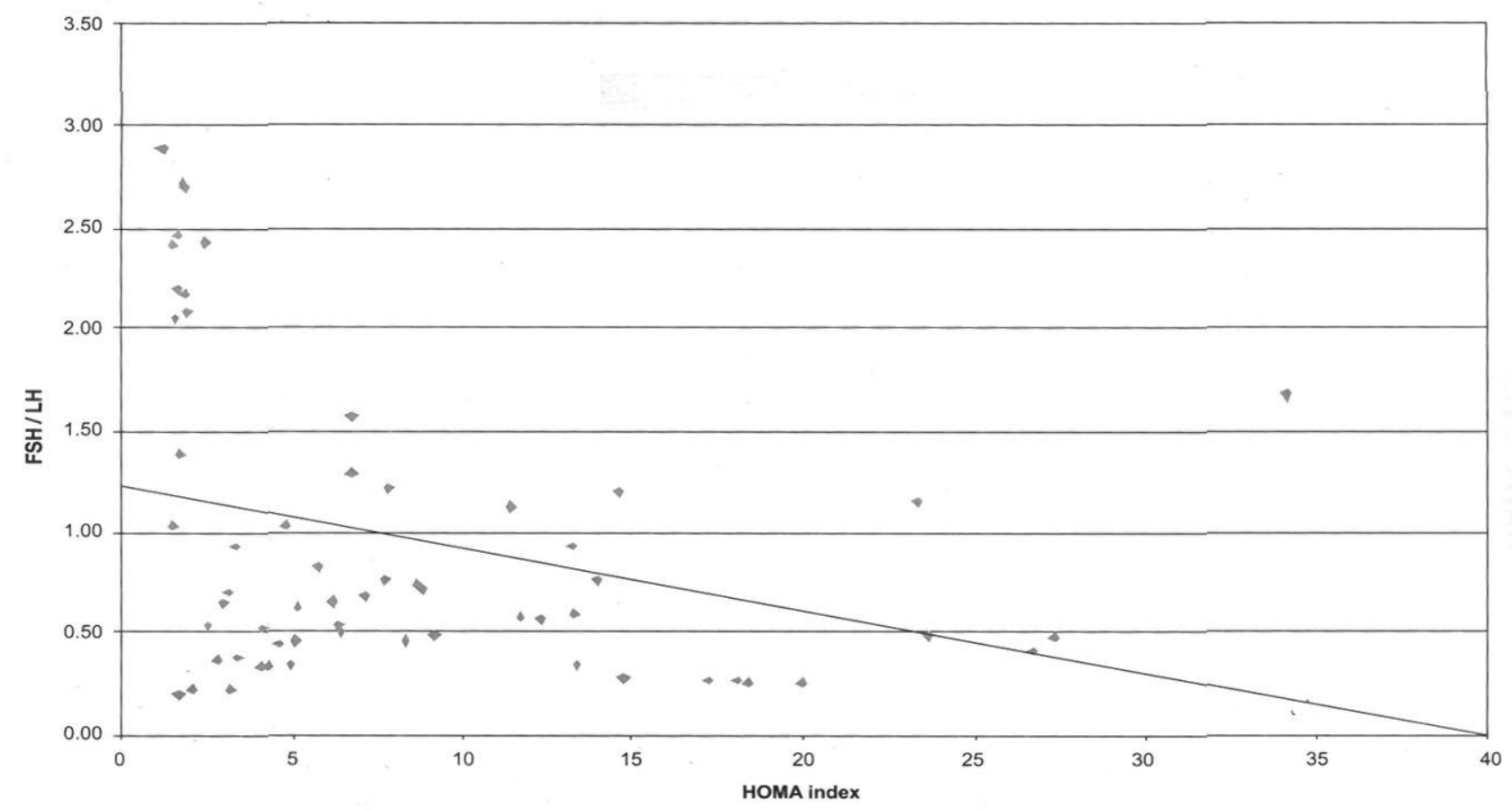

Figure 5 : Correlation between HOMA index level and FSH/LH in all groups.

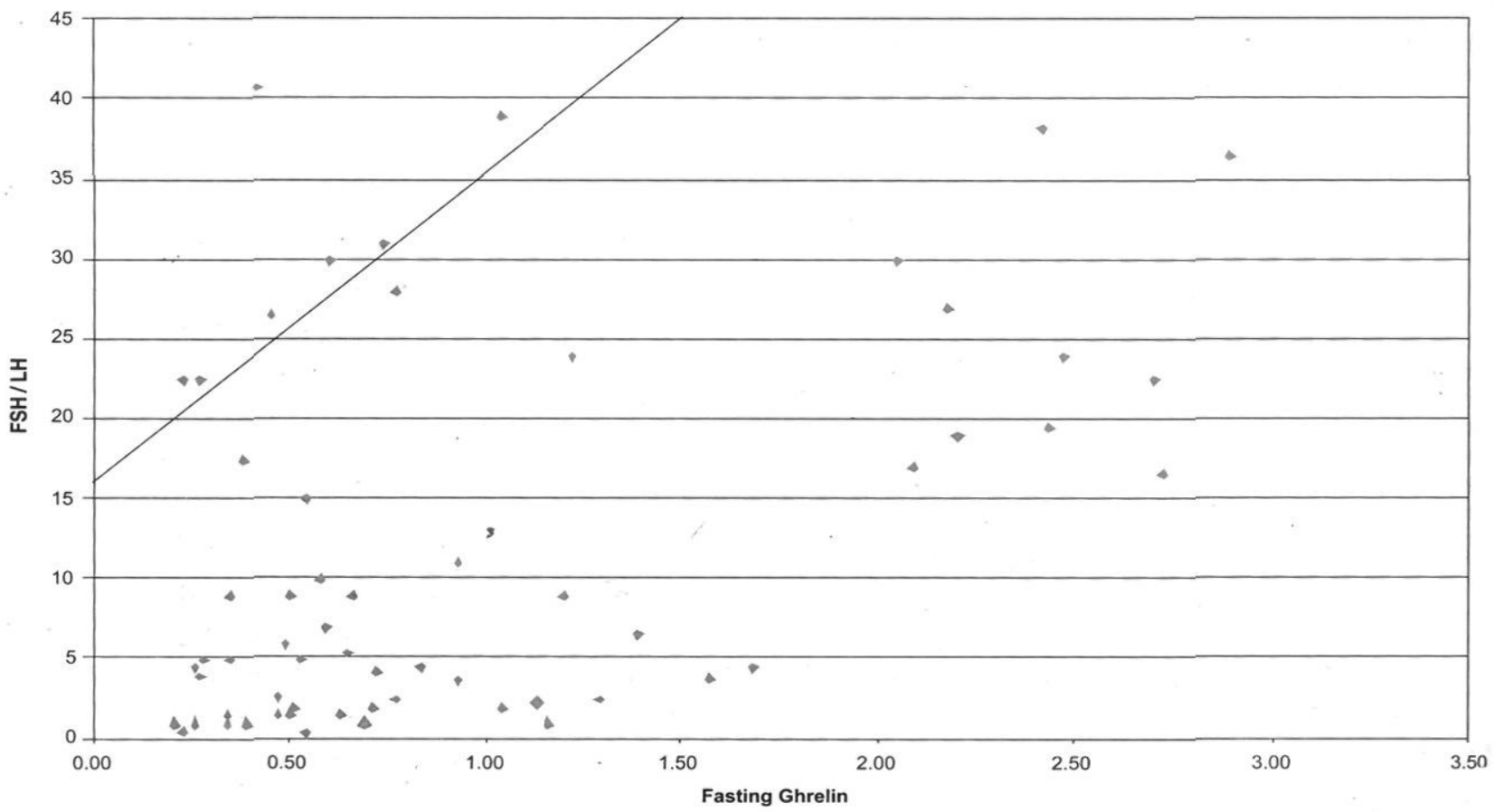

Figure 6 : Correlation between $\mathrm{FSH} / \mathrm{LH}$ and Fasting ghrelin level in all groups. 